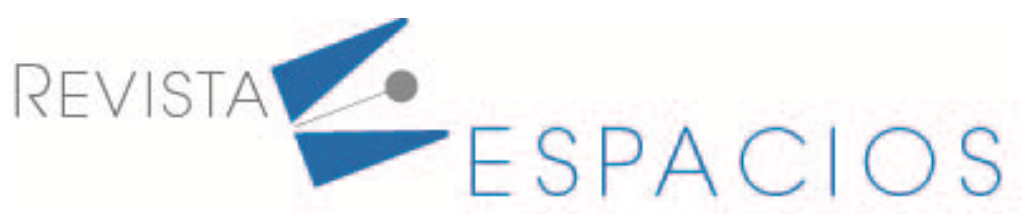

\title{
Accounting and analytical support for sustainable development of entities in agribusiness in Russia
}

\section{Soporte contable y analítico del desarrollo sostenible de empresas agrícolas en Rusia}

KHORUZHY, Liudmila I. ${ }^{1}$

KATKOV, Yuriy N. ${ }^{2}$

\begin{abstract}
This article is devoted to studying problems of accounting and analytical support to organisations in the agricultural sector. The article presents the authors' model of a stable accounting and analytical system developed taking into account specific features of agricultural production. The model offers an accounting and analytical register for assessing the sustainability level of organisations, and their corresponding scorecard.

Key words: Sustainable development, accounting and analytical system, agriculture, environment, social responsibility

Resumen

El artículo está dedicado al estudio de los problemas del soporte contable y analítico para las empresas del sector agrícola. Presenta el modelo de autor de un sistema sostenible de contabilidad y análisis, desarrollado teniendo en cuenta las particularidades de la producción agrícola. Se propone el registro contable y de análisis de autor para evaluar el nivel de sostenibilidad de las empresas, y una escala para su evaluación puntual.

Palabras clave: Desarrollo sostenible, sistema de contabilidad y análisis, agricultura, ecología, responsabilidad social
\end{abstract}

\section{Introduction}

Today's economy requires revising existing economic models, tools and social innovations, as well as setting new priorities and goals for the development of human civilisation. The emergence of the concept of sustainable development violated the fundamental basis of the traditional economy, which supposed unlimited economic growth. In one of the key documents of the UN Conference on Environment and Development (Rio De Janeiro, 1992) devoted to changes in the nature of production and consumption, there is a clear idea that it is necessary to abandon the traditional understanding of economic growth and switch to production and consumption patterns that would meet the essential needs of humanity (Voronkov, 2006).

Traditional economics states that satisfying consumers as much as possible, while simultaneously gaining maximum profit in a market system, is consistent with the highest wellbeing of people, and any market gaps can be adjusted by governmental policy. On the contrary, an economy built on the principles of sustainable

\footnotetext{
1 Professor. Russian State Agrarian University - MAA named after K.A. Timiryazev. Department of Accounting. Russia. Email: dka1955@mail.ru

${ }^{2}$ Associate professor, Russian State Agrarian University - MAA named after K.A. Timiryazev. Department of Economic Security, Analysis and Audit. Russia. Email: kun95@yandex.ru
} 
development supposes that short-term maximum results of business activities will ultimately result in the complete depletion of natural and social resources, the extinction of biological species and a strong deterioration in human wellbeing.

Transitioning to the concept of sustainable development is associated with the emergence of a new way of thinking, a new worldview. In an economy based on sustainable development, the environment, economics and society are not three different areas of knowledge and practice but are in fact closely interrelated, interdependent and mutually subordinated subsystems of a single whole.

Many organisations have not yet adopted sustainability principles, which is reflected in their unwillingness to comply with international environmental standards. To meet these standards, companies develop procedures, policies and systems aimed to continuously reducing their environmental impact. The principle of sustainability states that organisations can find ways to improve their wellbeing while preserving natural resources. Compliance with this principle is particularly important for agricultural organisations, which cannot operate without natural and biological resources.

Therefore, today's agricultural entities should revise their accounting and analytical systems to include environmental-oriented and socially-oriented aspects.

The purpose of this study was to create a model for a stable accounting and analytical system and to develop an analytical register for assessing the sustainability level of entities in the agricultural sphere, taking into account the current economic conditions on this business.

The stated goal has dictated the solution of the following tasks:

- to propose and substantiate a model of a stable record-keeping and analysis system developed with due regard for the peculiarities of agricultural production;

- to propose and substantiate a system of sustainable development indicators for assessment of agricultural companies;

- to develop a record-keeping and analysis register of assessment of the level of sustainability of agricultural companies.

\subsection{Literature review}

At present, there are a number of scientific materials related to the sustainability and organisational development of agricultural entities. Sustainable development issues have been addressed in studies by T.A. Akimova (2014), A.A. Bogdanov (2003), L. Brown (2003), V.I. Danilov-Danilyan (2000), O.V. Efimova (2014), K.S. Losev (2000) and Yu.N. Moseikin (2009).

Considering the essence of sustainable development, we will largely base our ideas on those of the outstanding Russian scientist A.A. Bogdanov (2003), who made a significant contribution to the development of organisational science. He outlined his logically constructed ideas on these issues in his fundamental work, "Tectology, Universal Organisational Science".

Bogdanov (2003) believed that the structural sustainability of the whole is defined by its least partial sustainability. In practice, a system is usually subject to uneven, rather than even, impacts in its various parts. Therefore, we have to introduce the concept of relative resistance of the elements in a complex at any given moment. Hence, the wording of the law: 'The sustainability of the whole depends on the lowest relative resistances of all its parts at any given moment'. 
Sustainability implies economic development that ensures better wellbeing and satisfaction of the living population's needs, while preserving the natural environment in a way that will allow future generations to have their needs met too (Daft, 2009).

Sustainable development entails harmonious, targeted and manageable processes of transforming human society, while simultaneously developing and maintaining the stability of all systems surrounding it (economic, political, environmental, social).

Issues about accounting and analytical support for organisations are considered in research by N.S. Batyrova (2014), I.V. Bryantseva (2003), E.V. Korchagina (2002), Kaplan (2005), Norton (2005) and E.Yu. Pertseva (2011).

The developmental stages of the structure and content of reporting from the middle ages to the present day, including analytical reporting, are disclosed in the works of Kuter, Gurskaya, Andreenkova and Bagdasaryan (2017).

Agriculture is distinguished by a variety of business types that evolve as a result of the impact of natural, climatic and economic factors. Agriculture is of great social importance, providing people with food and producing the raw materials needed to manufacture essential consumer goods.

In the production of agricultural products, the economy has the following specific features (Bryantseva, 2003):

- A close relationship between economic and biological processes on the production of agricultural products.

- Due to the natural biological processes of development and growth of living organisms, there is a cyclical nature of products made from them, which is seasonal.

- Agricultural production involves the active use of natural resources, where land is the main factor of production.

- The weather conditions in which an agricultural entity operates have a great impact on production.

The specific features considered above leave their mark on the evolution and operation of an accounting and analytical system in agriculture, which is dependent on the entity and specialisation of the agricultural production.

Environmental problems are unparalleled in terms of their negative impact on humanity and catastrophic consequences. Environmental issues are of paramount importance for business leaders, and for this reason, managers and organisations in all industries are starting to actively engage in environmental protection (Akimova \& Moseikin, Yu.N., 2009).

However, as far as Russia is concerned, there are currently no methods for developing the public economy that take into account a natural and environmental balance with minimum adverse impacts on the environment. It is therefore necessary to take measures to make the production activities of each entity more environmentallyfriendly. This is especially important for agribusiness entities, which have a complex structure and in which production processes are directly related to biological and natural resources. At the present stage of development, environmental aspects are reflected somewhat haphazardly; there is no comprehensive methodology for assessing and modelling the environmental consequences of economic activities in agricultural entities. The main tool designed to solve this problem at the enterprise level is the development and implementation of a management accounting system with elements of modelling, assessment and forecasting of environmental consequences. Despite the value of the research results, it should be noted that many theoretical and methodological problems of accounting and analytical support for organisations require further development. 


\section{Methodology}

This paper was prepared using the following research methods: monographic, calculation and design, abstract and logical, method of comparison, and simulation method.

As part of the management accounting system, an environmental programme should be developed, structured by environmental goals and objectives. These may include a list of activities, the expected results and benchmarks, the required resources, the deadlines for achieving objectives and the allocation of responsibility for achieving environmental goals and objectives for different functions and levels, for which this is appropriate within the entity.

Management accounting with an environmental focus centres in organisational activities and a reporting system within environmental responsibility for internal decision-making purposes. For those who make management decisions using such system, the information should include general provisions, policy context, alternative development options for the entity, public involvement, impact analysis, adverse impact mitigation and monitoring, conclusions and recommendations. Ensuring the analytical and sustainable nature of development in the existing environmental conditions of the entities' business, this management accounting system will actually meet the current economic realities.

In addition to environmental problems, organisations also face social problems. Currently, Russian business is trying to define the format of its social role. The main thing in this process is for the business to be aware of the conditions under which it will be of most interest to fulfil its social obligations and of what behaviour can be characterised as socially responsible. This context is largely due to the focus of Russian business on international integration and the concept of 'social responsibility' that has become part of global practice.

It should be noted that activities in the sphere of social responsibility are carried out by the business on a purely voluntary basis and are based on the understanding that being socially responsible in the modern world is not only necessary but also profitable, as they increase capitalisation and strengthen the sustainability and attractiveness of the business.

In this regard, entities need to functionally expand their management systems to include socially-oriented aspects. Therefore, in addition to introducing environmental aspects, we also suggest focusing management accounting on the social aspects of the organisations' activities.

Management accounting with a social focus is centred in organisational activities and a reporting system within the framework of social responsibility for internal decision-making purposes. It provides information about the company's activities resulting from both internal and external social responsibility. Internal social responsibility refers to the entity's policy with respect to its employees, which includes issues of employment, health and safety, stable and decent wages, additional medical insurance, training, professional development, etc. External social responsibility includes various charitable events, sponsorship, etc. Social accounting helps to reflect the entity's social policy and how this policy influences the performance of the entity on its reporting.

Reflecting activities related to an entity's internal social responsibility in socially-oriented management accounting is a recognition of the fact that human assets and human capital play an important role in the current economy. Human resource accounting is a process of identifying and measuring human resources, which includes evaluating costs incurred by entities to find, recruit, hire, train and develop personnel, as well as assessing their economic value for the entity. In other words, social accounting considers personnel as organisational resources necessary to achieve managerial and financial objectives. 
The social measurement of sustainable development refers to the impact of an entity on the social systems within which it operates. Social performance can be assessed by analysing the entity's impact on stakeholders on a local, national and global scale. In some cases, social indicators affect difficult-to-assess components of an entity's assets, such as human capital and reputation.

In a socially-oriented accounting system, it is also necessary to identify the social aspects of the reorganisation process. The social design stage describes the company, personnel, nature of works and incentives used in the reorganisation period and creates a plan for interaction of social and technical elements. At the same time, preliminary plans are prepared for hiring employees, their training and education and new staff placement.

Today's entities are responsible not only for their own resources but also for the economic resources of society, including natural and human resources, so the management of entities should be accountable to society for their use. In this regard, it is becoming increasingly important to assess the performance of entities using a system of indicators for all sustainable development areas in accordance with the concept of triple bottom line (TBL), which includes assessing a company's economic activity, its social policy and production environment. This system of indicators is provided by the recommendatory international standard "Global Reporting Initiative" (GRI), in the field of sustainable business (Voronova, 2011). These indicators make it possible to assess, optimise and manage entities' business activities in a comprehensive manner.

On this approach, the key criteria for optimisation are the reduction of natural resource intensity on production and the achievement of a proper ratio between the natural and production capacity of the territory. With regard to this, the natural resource intensity of production should not exceed the assimilation potential of the territory (environmental capacity). In addition, in a sustainable accounting and analytical system, special attention is paid to criteria relating to the social effect when increasing capitalisation and mitigating non-financial risks with a constant stable profit.

Therefore, we have proposed and described the component subsystems of a sustainable accounting and analytical system, which includes the assessment of social, economic and environmental performance. Such subsystems should not operate separately in entities, but instead, represent a single system with interrelated elements and a common working mechanism to ensure multi-level reporting that meets the requirements of the triple bottom line concept. Therefore, we present the authors' model of a stable accounting and analytical system, where analytical reporting is able to reveal economic, environmental and social indicators, combining them into consolidated statements (fig. 1).

In this figure, we can see that a sustainable accounting and analytical system consists of three subsystems that aim to create their own targets. At the same time, all three subsystems of management accounting are organised in one single system and are interconnected. In the sustainable accounting and analytical system shown above, there are both direct and inverse correlations, which constitute a certain element of sustainability. The reporting for each accounting subsystem can either be presented separately or consolidated with other subsystems.

However, despite the fact that a sustainable accounting and analytical system covers the economic component, as well as the social and environmental components, this makes it only partially sustainable. The fact is that current economic relations are very complex and a sustainable accounting and analytical system is not enough to ensure both sustainability of the entity and the system itself.

Therefore, it is necessary to consider other systems, tools and mechanisms that, along with management accounting, can provide entities with sustainable development. 
Figure 1

Model of a sustainable accounting and analytical system

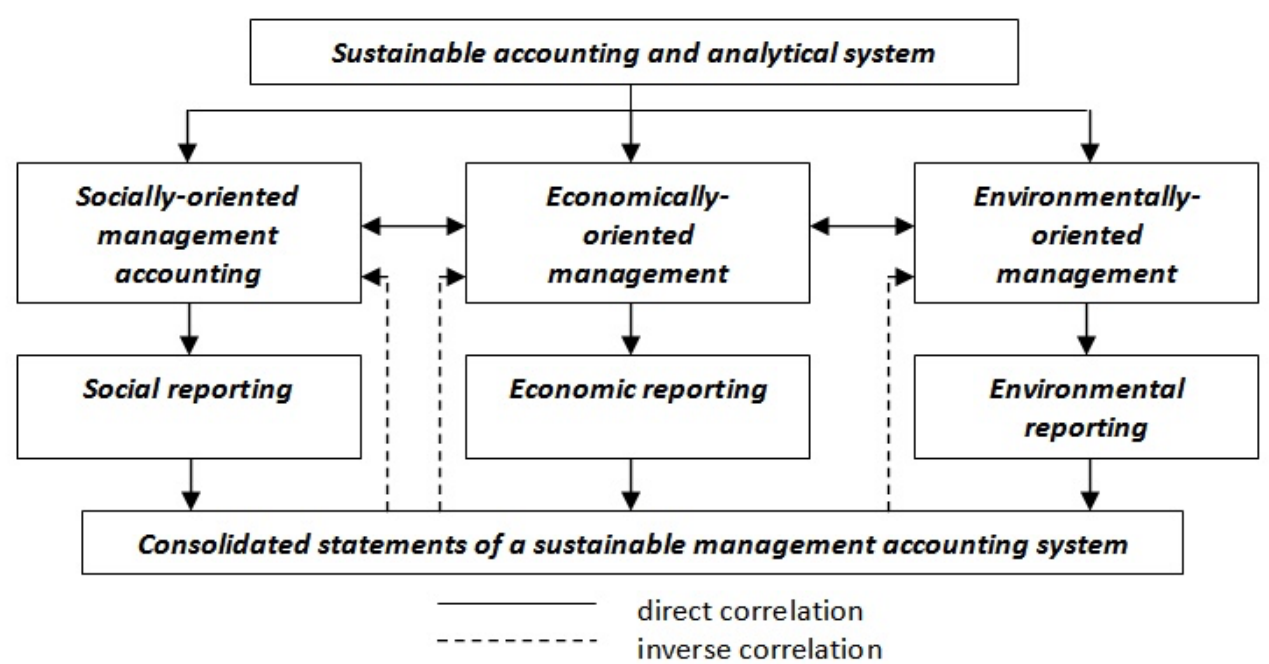

Source: the authors

\section{Results}

To implement the presented management accounting model in the practical activities of agribusiness entities, we have developed an accounting and analytical register for assessing the sustainability level (table 1), along with a scorecard for the indicators in this register (table 2).

The choice of indicators for assessing sustainable development in three areas is determined by our previous research on this topic (Khoruzhy, Karzaeva, Katkov, Tryastsina \& Ukolova 2018). The accounting and analytical register presented makes it possible to define the organisation's sustainability level both as a whole -for the entire business- and with a breakdown by economic, environmental and social aspects. By creating such registers, the management team within agricultural entities will have an efficient tool for rapid assessment, analysis and adjustment of business processes that affect their sustainable development.

In our example, after receiving the score, the entity falls within the medium sustainability level (table 1), which is a satisfactory position, however, as we can see from the register, the environmental and social indicators are poorly met. This means that this organisation needs to change its strategy for further development, paying more attention to the development of environmental and social aspects. Otherwise, the entity may lose its capacity for sustainable development in the near future. 
Table 1

Accounting and analytical register for assessing the

sustainability level of agribusiness entities in Russia

\begin{tabular}{|c|c|c|c|c|c|c|}
\hline $\begin{array}{l}\text { Item } \\
\text { No. }\end{array}$ & Indicators & UoM & Plan & Actual & Deviations & Score \\
\hline \multicolumn{7}{|c|}{ 1. Economic performance indicators } \\
\hline 1. & Sales revenue & RUB mln & 5,700 & 6,100 & 107.02 & 8 \\
\hline 2. & $\begin{array}{l}\text { Earnings before interest, taxes, depreciation } \\
\text { and amortisation (EBITDA) }\end{array}$ & RUB mln & 975 & 999 & 102.46 & 8 \\
\hline 3. & Return on Sales, Operating Margin (EBIT ROS) & $\%$ & 14.3 & 13.9 & 97.2 & 6 \\
\hline 4. & Return on Equity (ROE) & $\%$ & 3.4 & 3.5 & 102.94 & 8 \\
\hline 5. & Return on Invested Capital (ROIC) & $\%$ & 1.9 & 2.1 & 110.53 & 10 \\
\hline 6. & Return on Assets (ROA) & $\%$ & 1.63 & 1.7 & 104.29 & 8 \\
\hline 7. & Financial leverage & $\%$ & 32 & 27 & 84.38 & 4 \\
\hline \multicolumn{6}{|c|}{ Total for the first group of indicators } & 52 \\
\hline \multicolumn{7}{|c|}{ 2. Environmental performance indicators } \\
\hline 8. & True savings index & $\times$ & 0.8 & 0.7 & 87.5 & 4 \\
\hline 9. & $\begin{array}{l}\text { Environmental investments (\% of value added } \\
\text { created) }\end{array}$ & $\%$ & 5 & 4 & 80 & 2 \\
\hline 10. & $\begin{array}{l}\text { Initiatives to mitigate the environmental } \\
\text { impact of products and services }\end{array}$ & units & 7 & 5 & 71.43 & 2 \\
\hline 11. & $\begin{array}{l}\text { Economic damage from environmental } \\
\text { pollution (\% of the value added created) }\end{array}$ & $\%$ & 5 & 5 & 100 & 6 \\
\hline 12. & Provision of own environmental raw materials & $\%$ & 50 & 45 & 90 & 4 \\
\hline 13. & Share of secondary raw materials used & $\%$ & 10 & 9 & 90 & 4 \\
\hline 14. & $\begin{array}{l}\text { Number of significant accidents with } \\
\text { environmental damage }\end{array}$ & units & 0 & 0 & 100 & 6 \\
\hline Total & or the second group of indicators & & & & & 28 \\
\hline \multicolumn{7}{|c|}{ 3. Social performance indicators } \\
\hline 15. & $\begin{array}{l}\text { Number of cases of non-compliance with } \\
\text { regulatory requirements related to the impact } \\
\text { on health and safety of the entity's personnel }\end{array}$ & cases & 1 & 2 & 50 & 1 \\
\hline 16. & $\begin{array}{l}\text { Number of complaints accepted for } \\
\text { consideration by the management body of the } \\
\text { entity in order to monitor the safety of work }\end{array}$ & units & 2 & 2 & 100 & 6 \\
\hline 17. & Lost time due to accidents (total injury rate) & $\times$ & 120 & 115 & 95.83 & 6 \\
\hline 18. & $\begin{array}{l}\text { Average annual number of training hours per } \\
\text { employee per year }\end{array}$ & $\mathrm{h}$ & 24 & 36 & 150 & 10 \\
\hline 19. & $\begin{array}{l}\text { Percentage of employees whose interests are } \\
\text { represented by trade unions }\end{array}$ & $\%$ & 20 & 20 & 100 & 6 \\
\hline 20. & $\begin{array}{l}\text { Number of awards received for achievements } \\
\text { in public, ethical and environmental activities }\end{array}$ & pcs & 3 & 2 & 66.67 & 1 \\
\hline 21. & $\begin{array}{l}\text { Percentage of staff rotation within the } \\
\text { headcount (promotions) }\end{array}$ & $\%$ & 28 & 27 & 96.43 & 6 \\
\hline \multicolumn{6}{|c|}{ Total for the third group of indicators } & 36 \\
\hline \multicolumn{6}{|c|}{ Total for all indicators } & 116 \\
\hline \multicolumn{7}{|c|}{ Entity sustainability levels } \\
\hline 1 & High sustainability level & & & & \multicolumn{2}{|c|}{$140-210$} \\
\hline II & Medium sustainability level & & & & \multicolumn{2}{|c|}{ 69-139 } \\
\hline III & Low sustainability level & & & & \multicolumn{2}{|c|}{$21-68$} \\
\hline
\end{tabular}

Source: the authors 
Table 2

Scorecard of industrial safety indicators

\begin{tabular}{|c|c|}
\hline $\begin{array}{c}\text { Indicator value } \\
\text { Deviation in units of } \\
\text { measurement (\%) }\end{array}$ & Score \\
\hline Over 110 & 10 \\
\hline $101-110$ & 8 \\
\hline $91-100$ & 6 \\
\hline $81-90$ & 4 \\
\hline $71-80$ & 2 \\
\hline Under 70 & 1 \\
\hline
\end{tabular}

Source: the authors

\section{Conclusions}

In the scientific study previously presented, the following contributions can be highlighted:

- A Theoretical aspects, related to sustainable development of agricultural entities and their accounting and analytical support have been analysed;

- The need to introduce social and environmental aspects into an entity's accounting and analytical system for the analysis, assessment and management of these areas of the entity has been identified;

- A model of a sustainable accounting and analytical system for agribusiness entities has been created;

- An analytical register for assessing and determining the sustainability level for agribusiness entities has been developed.

Summarising the above, it can be concluded that for their successful and sustainable operation in the future, current agribusiness entities need to reorganise their management processes,focusing their business on taking into account the social, environmental and economic aspects of their activities.

In terms of tools, is the best done is to use the proposed model of a sustainable accounting and analytical system and to implement the assessment register presented. This will make it possible to receive consolidated analytical reports on activities of agribusiness entities and to implement social, environmental and economic management in an operational and strategic mode.

\section{Bibliographic references}

Akimova, T.A., Moseikin, Yu.N. (2009). The Economics of Sustainable Development. Moscow: Economics.

Batyrova, N.S. (2014). Information and Analytical Support for a Company's Sustainable Development Strategy. Auditor, 4(230), 79-86.

Bogdanov, A.A. (2003). Tectology. Universal Organisational Science. Moscow: Finance.

Brown, L. (2003). Eco-Economy: Building an Economy for the Earth. Moscow: Ves Mir.

Bryantseva, I.V. (2003). Economic Sustainability of an Enterprise. Khabarovsk: KhTGU.

Daft, R. L. (2009). Management. 8th ed. Saint Petersburg: Piter.

Danilov-Danilyan, V.I., Losev, K.S. (2000). Environmental Challenge and Sustainable Development. Moscow: Progress-Tradition. 
Efimova, O.V. (2014). Analysing and Assessing Performance of Business Entities in the Field of Sustainable Development. Accounting. Analysis. Audit, 1, 51-59.

Kaplan, R.S., Norton, D.P. (2005). The Balanced Scorecard: Translating Strategy into Action. Moscow: OlympBusiness.

Khoruzhy, L.I., Karzaeva, N.N., Katkov, Yu.N., Tryastsina, N.Y., Ukolova, A.V. (2018). Identification and Presentation of Information on Sustainable Development in the Accounting and Analytical System of the Organisation. International Journal of Civil Engineering and Technology, 9(10), 1575-1581.

Korchagina, E.V. (2002) Analysis and Assessment of Economic Sustainability in Business Structures. Saint Petersburg: SPb GUEF.

Kuter, M., Gurskaya, M., Andreenkova, A., Bagdasaryan, R. (2017). The Early Practices of Financial Statement Formation in Medieval Italy. Accounting Historians Journal, 44(2), 17-25.

Pertseva, E.Yu. (2011). Application of a Project Approach to Implementing a Company's Sustainable Development Strategy. Russian Journal of Project Management, 2(2), 16-21.

Voronkov, N.A. (2006). Environment: General, Social, Applied. Moscow: Agar.

Voronova, E.Yu. (2011). Management Accounting. Moscow: Urait.

Esta obra está bajo una Licencia Creative Commons Attribución-NoCommercial 4.0 International

\section{(cc) EY-NC}

